\title{
A Novel Combination Therapy in Aesthetic and Reconstructive Surgery: Sea Salt Exfoliation, Cavitating Ultrasound, and High Intensity Multiwavelength LED Treatment: (SaltFacial)
}

Greg Chernoff, BSc, MD, FRCSC*

Department of Otolaryngology, Head and Neck Surgery, Ascencion St. Vincent Hospital, Indianapolis, Indiana, USA

*Corresponding author: Chernoff G, Department of Otolaryngology, Head and Neck Surgery, Ascencion St. Vincent Hospital, Indianapolis, Indiana, USA, Tel: +1-317-573-8899; Fax: +1-317-818-2008; E-mail: greg@drchernoff.com

Received: 15 Mar, 2021 | Accepted: 30 Apr, 2021 | Published: 08 May, 2021

Citation: Chernoff G (2021) A Novel Combination Therapy in Aesthetic and Reconstructive Surgery: Sea Salt, Exfoliation, Cavitating Ultrasound, and High Intensity Multiwavelength LED Treatment: (SaltFacial). J Clin Cosmet Dermatol 5(2): dx.doi.org/10.16966/2576-2826.162

Copyright: (C) 2021 Chernoff G. This is an open-access article distributed under the terms of the Creative Commons Attribution License, which permits unrestricted use, distribution, and reproduction in any medium, provided the original author and source are credited.

\begin{abstract}
Introduction: The science in aesthetic medicine continues to grow and expand exponentially. With improved science comes advanced clinical therapeutics that further benefits our patients. Physicians are seeking non-surgical technologies that are capable of safely treating all Fitzpatrick skin types while yielding meticulous results.

This study examines the safety and potential efficacy of a new instrument platform offering single session sea salt exfoliation in combination with cavitating cutaneous ultrasound and high intensity LED light therapy (SaltFacial) in treating aging skin, acne, infection, edema and wound healing.
\end{abstract}

Method: The safety of each of these modalities has been established individually in the peer reviewed literature. There has not been a study comparing the efficacy of combining these technologies in a single session to traditional treatments such as microdermabrasion and hydrating facials, potentially adding benefit to the patient. This study examines performing the SaltFacial on the 20 aging skin patients, 16 acne patients, 16 patients with post-surgical infection, and 40 patients with post-surgical edema, bruising, and actively healing wounds. The treatment group was compared to an equal number of patients in a control group who were matched for sex and age, treated with what is considered "standard of care" treatment for the specific conditions studied. Patient results were objectified with standardized photography, and the Quantificare 3D Imaging System Software (Quantificare, USA), which measures depth of wrinkles, pore size, general evenness, oiliness, unwanted pigment and redness. Linear analog scores were also administered to patients measuring treatment satisfaction and pain experienced.

Results: There were no adverse reactions in any patient from the sea salt exfoliation, ultrasound therapy, or LED light treatment, alone or in combination with each other.

In the Aging Skin Population, the SaltFacial proved more efficacious than microdermabrasion or hydrating facials. Uniformly, Quantificare analysis measurements were better for wrinkle reduction, pore size reduction, improved skin evenness, reduced oiliness, reduced pigmentation, and reduction of unwanted blemishes in the SaltFacial patients than microdermabrasion or hydrating facials alone. These results were further improved when a nitric oxide generating serum (N101, Pneuma Nitric Oxide, USA) was utilized as the ultrasound "glide" primer prior to administering protein peptides. Patient Linear Analogs showed the majority of patients to be "extremely happy" or" happy" with the combination treatment results. No patients expressed "displeasure" with the combination treatment results. This combination treatment can therefore serve as a "non-thermal" form of skin rejuvenation, comparable to Fractionated $\mathrm{CO}_{2}$ or radiofrequency systems.

The Acne Patient Population showed a reduction in pustules and comedones 4 weeks after weekly SaltFacial combination treatments compared to a control population receiving oral and topical antibiotic treatment alone. Acne-induced inflammation and erythema was reduced by $72.5 \%$ in SaltFacial patients as compared to $36.8 \%$ in the antibiotic patients.

The Post-Surgical Infection Patients showed uniform rapid resolution of infection, inflammation, erythema and pain (mean 5.8 days) subsequent to the high-intensity LED light therapy as compared to patients similarly infected in corresponding regions treated only with traditional culture-specific antibiotic therapy(11.4 days) and accepted wound care. This was shown in challenging MRSA infections which can yield devastating results if not treated promptly and appropriately. 
The Post-Surgical Wound Healing SaltFacial Patient Population showed more rapid healing (mean 6.9 days) as compared to the control patient population (mean 11.1 days) receiving traditional corticosteroid therapy alone. Eighty-five percent of patients reported less edema, erythema and discomfort by day 10 as compared to $18 \%$ of control patients. The anti-prostaglandin effect of LED light therapy was also demonstrated with $76 \%$ of LED-treated patients reporting less pain as measured by linear analog scores compared to $10 \%$ of control patients.

The Wound Healing Patient Population also showed more rapid re-epithelialization, faster edema and purpura resolution as well as more aesthetically pleasing scars compared to control patients who received traditional standard of care wound care.

Conclusion: The SaltFacial shows benefit in the aging skin, acne, infection, inflammation and wound healing patient populations.

The sea salt component lends antibacterial, antifungal and antiviral benefits. Additionally, sea salt promotes healing via normal $\mathrm{pH}$ maintenance, barrier function protection and mineral and vitamin deposition. Ultrasound penetration is also enhanced.

The topical minerals, particularly calcium and magnesium aid in neocollagenesis and keratinocyte production improving the overall tone, quality and clarity of skin.

The cavitating ultrasound improves circulation, facilitates tissue permeability of dermal beneficial products and promotes a healthy immune cellular response.

LED phototherapy acts as an anti-bacterial, anti-fungal, and anti-viral tool. Additionally, LED light reduces inflammation, increases dermal collagen synthesis, and dramatically reduces pain by down regulating pain receptors.

This novel combination therapy yields a valuable addition to the armamentarium of the aesthetic and reconstructive physician.

\section{Introduction}

The concept of "Generational Aesthetics" is important to understand in the current arena of products and services offered by aesthetic providers. The current demographic distribution of aesthetic patients in most practices includes: generation $\mathrm{Z}$ patients (12-25 years), millennials (26-40 years), generation $X$ patients ( $41-55$ years), baby boomers (56-75 years), and with improved health care, more 76-to 90-year-old patients are also seeking consultations for skin maintenance and improvement.

While the individual needs of these groups differ proportionate to genetics, age, diet, hormonal levels, environmental exposure, and degree of self-care, common to all; is the desire to obtain "preventative regimens" over "corrective regimens". In addition to prevention, more patients are seeking non-surgical, minimally invasive alternatives to surgical intervention for aesthetic improvement. Minimal to no downtime tops the list for this reasoning.

The main signs of aging common to men and women include bone resorption, gravitational muscular decent, volume loss, and loss of elasticity, tone, quality and clarity of skin. It behooves the treating physician to recommend the safest, most efficacious treatment to yield the best, longest lasting solution. If muscular gravitational decent is the chief complaint, then surgical interventions such as brow lift, eyelidlift or face/neck lift are typically the best long-term solutions. Volume loss can be remedied with fat transfer or commercially available injectable fillers. When loss of elasticity, tone, quality and clarity of skin are more concerning than muscular gravitational descent or volume loss, then non-surgical skin improving options are realistic to achieve realistic goals.

Technological advancements have risen in skin quality improvement systems over the past decades. Both ablative and non-ablative systems have seen refinements. Light and energy-based therapies have sought higher intersecting lines of safety and efficacy. Minimally invasive treatments heralding minimal risk, minimal downtime, and minimal pain have added to the armamentarium of treating physicians. Four of these individual treatments include microdermabrasion, hydrating facials, cavitating ultrasound, and LED phototherapy.

Traditional microdermabrasion systems shoot a stream of fine crystals such as aluminum oxide, sodium chloride or sodium bicarbonate with the intent of disrupting and removing all or part of the stratum corneum. With this in mind, a more accurate name would be "microepidermabrasion", as there is little effect on the dermis. A suction device removes the dead cells and the used crystals. The act of removing the stratum corneum allows for improved absorption of topical products and the replacement by the body with younger, healthier epidermal cells.

In recent years, research has focused on refining the media used to remove the stratum corneum. This research focused on finding an exfoliation medium that could have ancillary dermal benefits in addition to exfoliative capabilities.

Salt is one of the potential candidates. Much has been written on the history of salt [1]. For hundreds of years, this substance has served as a currency, influenced the establishment of trade routes and cities, provoked and financed wars, and inspired revolutions and secured empires. There is some misunderstanding in the lay population as to the types of salt. From a health perspective, there is "bad" salt, and "good" salt. Bad salt is processed and refined. It typically contains 97.5\% sodium chloride $(\mathrm{NaCl})$ and $2.5 \%$ chemical additives which when overused can lead to hypertension and cardiac disease. Good salt is unrefined, typically found in ocean and sea salt, or in pristine salt mines. Sea salt is composed of $85 \% \mathrm{NaCl}$, and $15 \%$ of 60 trace minerals such as $\mathrm{Mg}, \mathrm{Ca}, \mathrm{Na}$, and $\mathrm{K}$.

There has been growing evidence that the well-being of our skin is strongly influenced by nutrition, particularly vitamin and mineral content [2]. Twelve vitamins and nine minerals are thought to be essential for healthy enzymatic bodily function. The vitamins include vitamins $\mathrm{A}, \mathrm{D}, \mathrm{C}, \mathrm{E} \mathrm{K}, \mathrm{B} 6, \mathrm{~B} 12$, thiamin, riboflavin, niacin, folate, and choline. The minerals include calcium, copper, iron, magnesium, phosphorus, selenium, zinc, potassium, and sodium. While some 
topical application studies exist, the benefits of topically applied mineral salts to the skin have been largely unexplored. To date, topical sea salt has been found to be antibacterial, antifungal, antiviral, and hydrophilic in protecting the hydration barrier, detoxifying and immunomodulatory [2].

Cavitating ultrasound is another modality which has shown scientific benefit to skin health [3]. Traditional topical delivery of products to tissue is limited by epidermal permeability and dependent upon the molecular size and weight of the product being applied, and the existing circulation of the recipient tissue bed. Cutaneous ultrasound has been shown to improve circulation and increase tissue permeability, thereby increasing the depth of penetration and absorption of topically applied substances [4]. When focused deeper, with higher intensity, cavitating ultrasound has been shown to successfully reduce adipocytes and improve lymphatic drainage [5].

LED therapy has also been investigated for skin health [6]. The most common and beneficial wavelengths include blue $(414 \mathrm{~nm})$, which has been shown to be bactericidal, red $(660 \mathrm{~nm})$, which can reduce inflammation and induce cellular proliferation, amber $(590 \mathrm{~nm})$ which has ant-inflammatory benefits, and infrared $(830 \mathrm{~nm})$ which improves vascularity and collagen production [6].

To date, there has not been a single instrument platform, or a study that combines, in a single treatment session, these modalities. The purpose of this study is to examine the potential efficacy of these modalities combined in a single treatment session in treating aging skin, acne, infections, and wound healing and other cutaneous problems.

\section{Methods}

This study examines combination single session therapy utilizing sea salt exfoliation, cavitating ultrasound with dermal deposition of a hyaluronic acid peptide serum containing acetyl hexapeptide, palmitoyl pentapeptide, and palmitoyl oligopeptide (Abbe Labs, New York, NY), followed by endpoint focused, wavelength specific, high-intensity LED light exposure, (SaltFacial, USA).The sea salt for the SaltFacial is harvested from the waters of the San Francisco Bay, processed, purified and re-crystallized to produce an extra-fine particle size. The sea salt is composed of $85 \% \mathrm{NaCl}$, and $15 \%$ of 60 trace minerals such as $\mathrm{Mg}, \mathrm{Ca}, \mathrm{Na}$, and $\mathrm{K}$.

The SaltFacial Treatment Patient Population included 20 aging skin patients, 16 acne patients, 16 patients with post-surgical infection, and 40 patients with post-surgical edema, bruising, and actively healing wounds located on the face and neck. The control group contained an equal number of patients, matched for sex and age within each subgroup above.

The Aging Skin Patients consisted of 15 females and 5 males. Ages ranged from 36-73 years. There were 6 Caucasian, 3 Asian, 4 Hispanic, 4 African American, 3 Indian, and 1 Mediterranean patient. The Acne Patients consisted of 12 females and 4 males. Ages ranged from 15 to 34 years. There were 8 Caucasian, 2 Asian, 4 Hispanic, and 2 Indian patients. The Infection Patients consisted of 16 females. Ages ranged from 42 to 73 years. All were Caucasian. The Post-op edema/bruising/ Wound Healing Patients consisted of 32 females and 8 males. All were Caucasian.

The Aging Skin Patients first received the sea salt exfoliation. This was followed by a 3-megahertz $(3 \mathrm{MHz})$ ultrasound application of Nitric Oxide generating serum (N101, Pneuma Nitric Oxide, USA), followed by the peptide serum. Topical nitric oxide has been shown to dramatically increase dermal vascularity, absorption, and act as a vehicle for enhanced absorption of other topicals [7]. It is generated topically subsequent to mixing Vitamin $\mathrm{C}$ serum and a serum containing sodium nitrite [7]. This was followed by the high intensityLED phototherapy module which consisted of 4 condition specific wavelengths. The light emitting diodes are contained in 3 panels on an articulated arm. The panels can be positioned flat or articulated at 90 degrees to each other, yielding a wrap around effect to the patient's head and neck. The aging face patients received 20 minutes of red $(660 \mathrm{~nm}) /$ near infrared $(930 \mathrm{~nm}) @ 186 \mathrm{~J} / \mathrm{cm}^{2}, 20 \mathrm{~mW} / \mathrm{cm}^{2}$ therapy. Each patient received a full treatment at 30,60 and 90 days. The control group was randomized, and received either traditional microdermabrasion or a hydrating facial administering the same peptide serum. Linear analogs were administered at each treatment session and finally at 120 days. Patients were given a $10 \mathrm{~cm}$ line, the left side representing no benefit, and the right side representing maximal benefit. They placed a mark on the line representing their perceived benefit from each respective treatment. This yielded a number out of 10 , subjected to statistical analysis. Standardized color photography was performed prior to each session and at 120 days. Patient results were objectified at 30-day intervals with standardized photography, as well as the Quantificare 3D imaging system (Quantificare, USA), which measures depth of wrinkles, pore size, general evenness, oiliness, unwanted pigment and redness (Figure 1). Linear analog scores were also administered to patients measuring treatment satisfaction and pain experienced. Quantificare analysis was performed at 30 and 120 days.

The Acne Patients received salt exfoliation, cavitating ultrasound, and 20 minutes of red (660nm)/blue $(414 \mathrm{~nm}) @ 106 \mathrm{~J} / \mathrm{cm}^{2}, 20 \mathrm{~mW} / \mathrm{cm}^{2}$ LED therapy at each treatment session. Treatments were performed at 7 day intervals for 21 days ( 3 treatments). Standardized photography and Quantificare analysis were performed prior to each session and finally on day 28 . Linear analogs were administered at each session and on day 28.

The Infection Patients received 20 minutes of red $(660 \mathrm{~nm}) / \mathrm{blue}$ (414nm)@ $106 \mathrm{~J} / \mathrm{cm}^{2}, 20 \mathrm{~mW} / \mathrm{cm}^{2}$ LED therapy daily for 10 days. Photography and quantificare analysis were performed prior to the initiation of treatment and on the final day of treatment.

The Wound Healing Patients received 20 minutes of red $(660 \mathrm{~nm}) / \mathrm{amber}(660 \mathrm{~nm}) @ 142 \mathrm{~J} / \mathrm{cm}^{2}, 20 \mathrm{~mW} / \mathrm{cm}^{2}$, daily for 10 days. Photography was performed prior to the initiation of treatment and on the final day of treatment. Exclusion criteria in this study included an unwillingness to avoid excessive sunlight or wear protective clothing and sunscreen, unwillingness to forgo any other topical dermatological or drug therapy, the use of topical corticosteroid, alpha and betahydroxy acids, retinoids, or vitamin-C containing topicals within 30 days before, as well as throughout the course of the study. Washout periods adhered to by subjects in this study included 6 months free from dermabrasion, deep chemical peels, ablative laser treatments, and neurotoxin or filler injections: 3 months free from non-ablative laser, light, radiofrequency or ultrasound treatments; and 1 month free from microdermabrasion, light and medium depth peels.

The Aging Skin Patients were compared to a control population undergoing traditional microdermabrasion followed by a hydrating facial treatment utilizing standard parameters for those technologies.

The Acne Patients were randomized equally into a SaltFacial treatment group, and a control group. The control group received clindamycin $150 \mathrm{mg}$ bid, and $1 \%$ clindamycin topical solution bid.

The Infection Patients were randomized equally into a SaltFacial treatment group and a control group. The control population received antibiotic therapy alone, specific to bacterial culture results, collected 
Wrinkles: Combination of depth, length, and width

of the main wrinkles in the region of interest.

Pores: The deepest pores in the region of interest expressed as a percentge of all identifiable pores.

Evenness: a global measurement of skin surface irregulaity in the region of interest depending on the fine or coarse texture of the skin.

Oiliness: Shiny parts of the skin, in association with pores, highlighting parts exhibiting sebum abnormalities.

Brown Spots: Skin areas which are potentially predisposed to age spots (sun damage). It may also indicate lentigo, freckles, moles, and other similar spots with higher concentration of melanin.

Red Spots: Part of the skin exhibiting redness, including birthmarks, telagiectasia, rosacea, acne, rash, scab, erythema, and everything relative to vascularization and hemoglobin.
Definition of scores for wrinkles, pores, evenness, oillness: Skin health against a population based on matching correspondence of age, gender, and skin type.

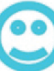

$$
\begin{aligned}
& +10 \text { the top } 2,5 \% \text { of best subjects, } \\
& +\quad+5 \text { the top } 16 \% \text { of best subjects, } \\
& -0 \text { is average, } \\
& -5 \text { the bottom } 16 \% \text { of worst subjects, } \\
& -10 \text { the bottom } 2,5 \% \text { of worst subjects. }
\end{aligned}
$$

Figure 1: Quantificare skincare tests and score definitions.

by cutaneous swab specimens before treatment and 5 days after treatment.

The Inflammation/Bruising/Wound Healing Population was randomized equally into a SaltFacial treatment group and a control group. The control population received standard postoperative corticosteroid (Medrol Dose Pack) and antibiotic therapy (Cephalexin, $500 \mathrm{mg}$, po, bid for 7 days).

Data were analyzed with IBM SPSS statistics (Version 23: IBM Inc, Armonk, New York). Data was analyzed with the student's t test, paired sample $t$ tests and one-way analysis of variance (ANOVA). $\mathrm{P}$ values were assumed significant when $<.05$.

\section{Results}

There were no adverse events attributable to the salt exfoliation, cavitating ultrasound, or LED therapy in the entire study patient population. In particular, there were no allergic, or hypersensitivity reactions, abrasions, or ultrasound/light burns. No patients experienced claustrophobic symptoms due to the proximity of the wrap around LED panels. No patients experienced discomfort or pain that forced cessation of treatment.

The Aging Skin Patients uniformly showed by Quantificare analysis a reduction of wrinkles, pore size, unwanted pigment, and improvement in general oiliness, texture and vascularity of their skin (Figure 2). Each category showed a greater improvement than those patients undergoing traditional microdermabrasion (Figure 3), or a hydrating facial (Figure 4). The degree of improvement increased with each subsequent treatment up to the 120 day period (Figure 5). Patient linear analog scores (Figure 6) showed progressive patient satisfaction with each consecutive treatment (Table 1). There were no unhappy patients treated in the SaltFacial Group. By day $120,80 \%$ reported being extremely satisfied, $10 \%$ were very satisfied and $10 \%$ were satisfied.
Table 1: Aging Skin: Summary of the results of patient administrated linear analog tests for satisfaction.

\begin{tabular}{|l|c|c|c|c|}
\hline \multirow{2}{*}{ Satisfaction } & \multicolumn{4}{|c|}{ Percent } \\
\cline { 2 - 5 } & 30 Days & $\mathbf{6 0}$ Days & $\mathbf{9 0}$ Days & $\mathbf{1 2 0}$ Days \\
\hline Unhappy & 0 & 0 & 0 & 0 \\
\hline Satisfied & 75 & 50 & 10 & 10 \\
\hline Very Satisfied & 15 & 10 & 15 & 10 \\
\hline Extremely Happy & 10 & 40 & 75 & 80 \\
\hline
\end{tabular}

The Acne Patients showed a $72.5 \%$ mean reduction of pustules and comedones (Table 2) compared to a $36.8 \%$ mean reduction $(\mathrm{p}<.0001)$ in the control patients treated with antibiotics alone by day 28 (Figure 7). The degree of improvement increased with each subsequent treatment from Day 7 to Day 28 (Figure 8). Linear analog scores showed a progressive increase in satisfaction with each subsequent treatment (Table 3 ). There were no unhappy patients in the SaltFacial group. By 28 days, $87.5 \%$ reported that they were extremely satisfied, and $12.5 \%$ reported that they were very satisfied with the treatment.

The Active Infection Patients (Figure 9) showed a faster time of tissue culture resolution with a mean of 5.8 days, than the control group with a mean of 11.4 days $(p<.0001)$ on oral and topical antibiotics alone (Table 4). Linear analog scores also showed a significant reduction in pain when treated with the LED therapy compared to antibiotics alone (Table 5) with $87.5 \%$ reporting to be extremely satisfied and 12.55 reporting to be very satisfied. There were no patients unhappy with the treatment.

The Post-Surgical Edema and Bruising Patients (Figure 10), showed a faster resolution with a mean of 6.95 days when treated with LED therapy than the control group, mean of 11.1 days $(\mathrm{p}<0001)$ that were treated with standardized oral corticosteroid therapy alone (Table 6). Eighty-five percent of the SaltFacial group reported less edema, 


\section{Skincare analysis before SaltFacial treatment.}
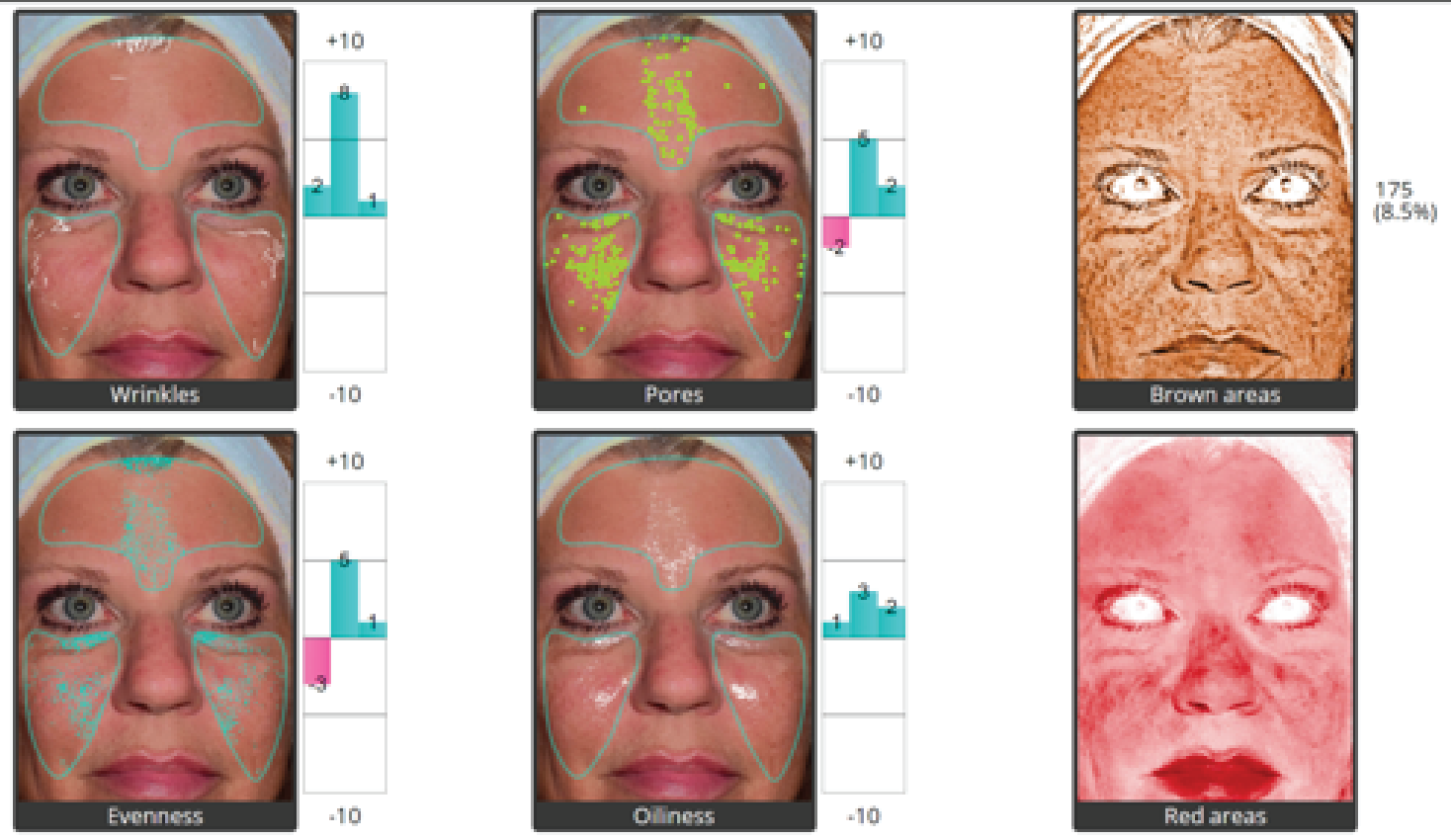

Skincare Analysis 30-days after $1^{\text {st }}$ SaltFacial treatment.
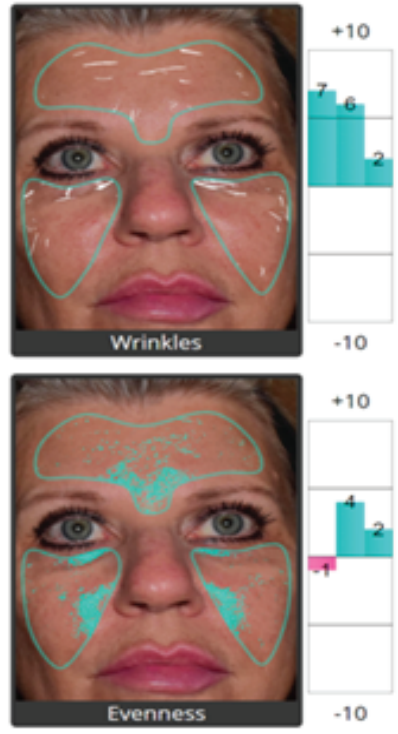

$-10$
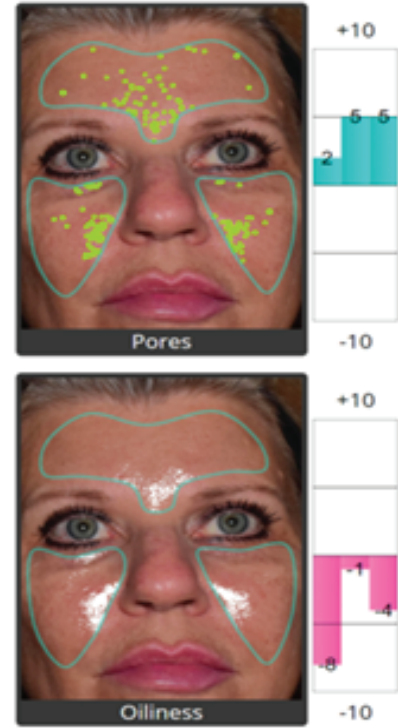

$+10$

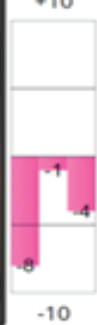

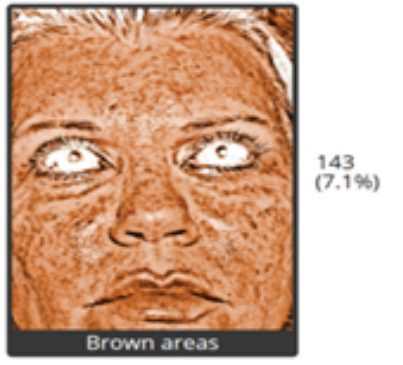

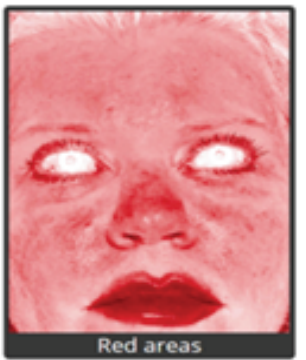

Figure 2: Aging skin patient: Note improvement in graphs after salt facial.

bruising and discomfort by day 10 compared to only $10 \%$ of the control group. Seventy-six percent of the SaltFacial group reported less pain from the onset of treatment resulting in less pain medication consumed, compared to only $10 \%$ of the control group.

\section{Discussion}

As the age demographic of patients seeking aesthetic improvement widens from Generation Z (12-25 years) to patients in their 70's and 80 's, demand for non-surgical alternatives is also increasing. Systems having high intersecting points of safety and efficacy, providing patients with focused end-point results with minimal risk, minimal discomfort, and minimal downtime continue to see interest and implementation by treating physicians.

This study examines the combination of three modalities into a single treatment platform, as compared to microdermabrasion or hydrating facials alone. These include sea salt exfoliation, cavitating ultrasound to improve circulation and tissue permeability, and high intensity end point focused, wavelength specific LED phototherapy 
Skincare analysis before-microdermabrasion.

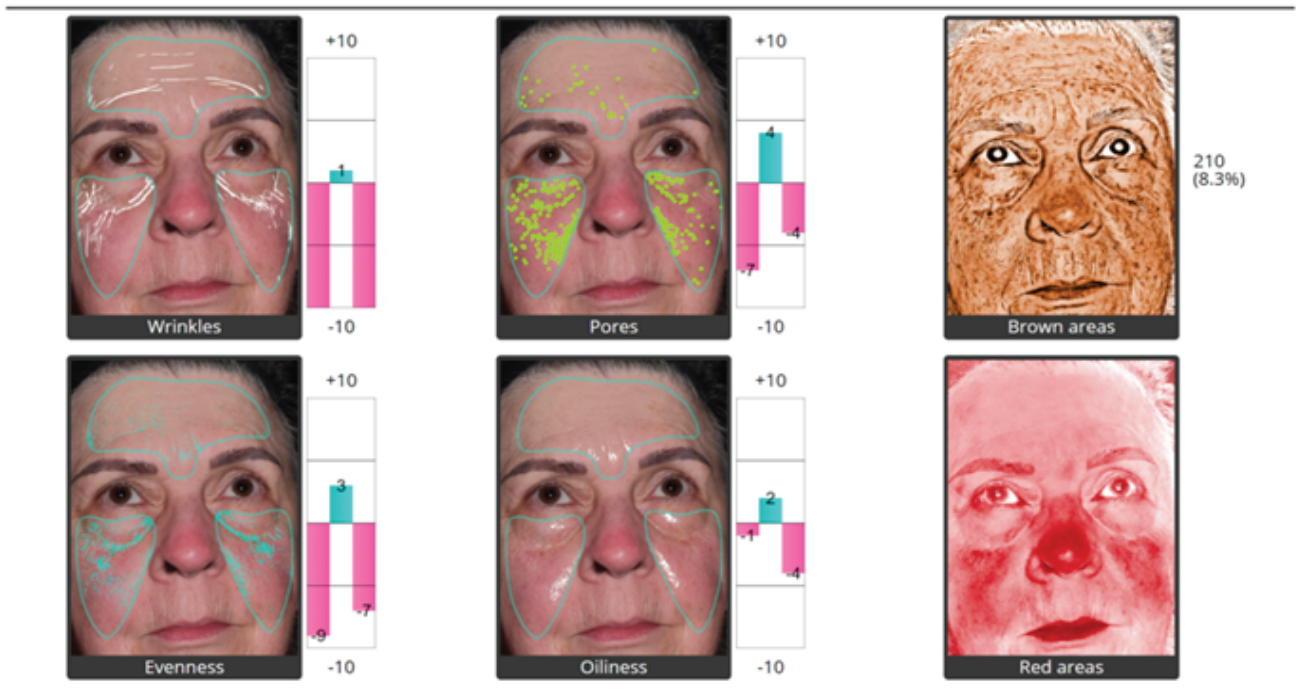

Skincare Analysis after - microdermabrasion - note minimal change in graphs.
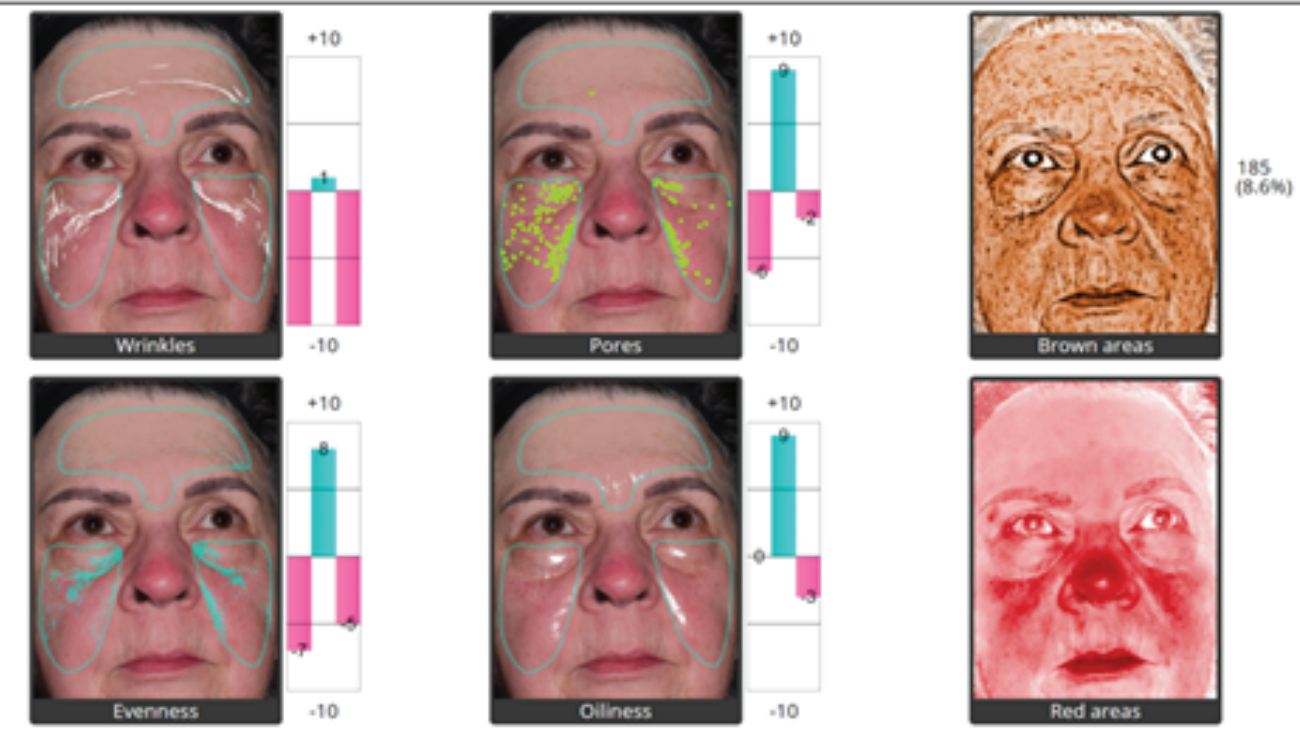

Figure 3: Skincare analysis before and after microdermabrasion.

Table 2: Acne Patient: Percent improvement pustules/Comedones compared to control Antibiotic alone patients.

\begin{tabular}{|c|c|c|c|}
\hline Salt Facial & $\begin{array}{c}\text { \%Improvement-28 } \\
\text { Days }\end{array}$ & Control & $\begin{array}{c}\text { \%Improvement-28 } \\
\text { Days }\end{array}$ \\
\hline 1 & 65 & 1 & 40 \\
\hline 2 & 75 & 2 & 30 \\
\hline 3 & 50 & 3 & 60 \\
\hline 4 & 80 & 4 & 50 \\
\hline 5 & 90 & 5 & 10 \\
\hline 6 & 75 & 6 & 50 \\
\hline 7 & 70 & 7 & 35 \\
\hline 8 & 75 & 8 & 20 \\
\hline
\end{tabular}

(SaltFacial). Each of these modalities individually have undergone scientific peer reviewed scrutiny. This is the first study examining the benefit of concomitant utilization.

Why sea salt? Historically, for thousands of years, salt has played a central role in developing civilization [1]. It has served as a currency, influenced the establishment of trade routes and cities, provoked and financed wars, and inspired revolutions and secured empires. For centuries, salt was used medically for its cleansing and healing properties, revealing it to be antibacterial, antimicrobial, a natural humectant, aiding in balancing $\mathrm{pH}$, improved permeability, and reducing inflammation [1]. Sea salt and salt from pristine salt mines is comprised of $85 \% \mathrm{NaCl}$, and $15 \%$ trace minerals. Processed or refined salt contains $97.5 \% \mathrm{NaCl}$, and $2.5 \%$ toxic chemical additives which have been related to disorders such as hypertension and other cardiac diseases [1]. 
Skincare analysis before - hydrating facial

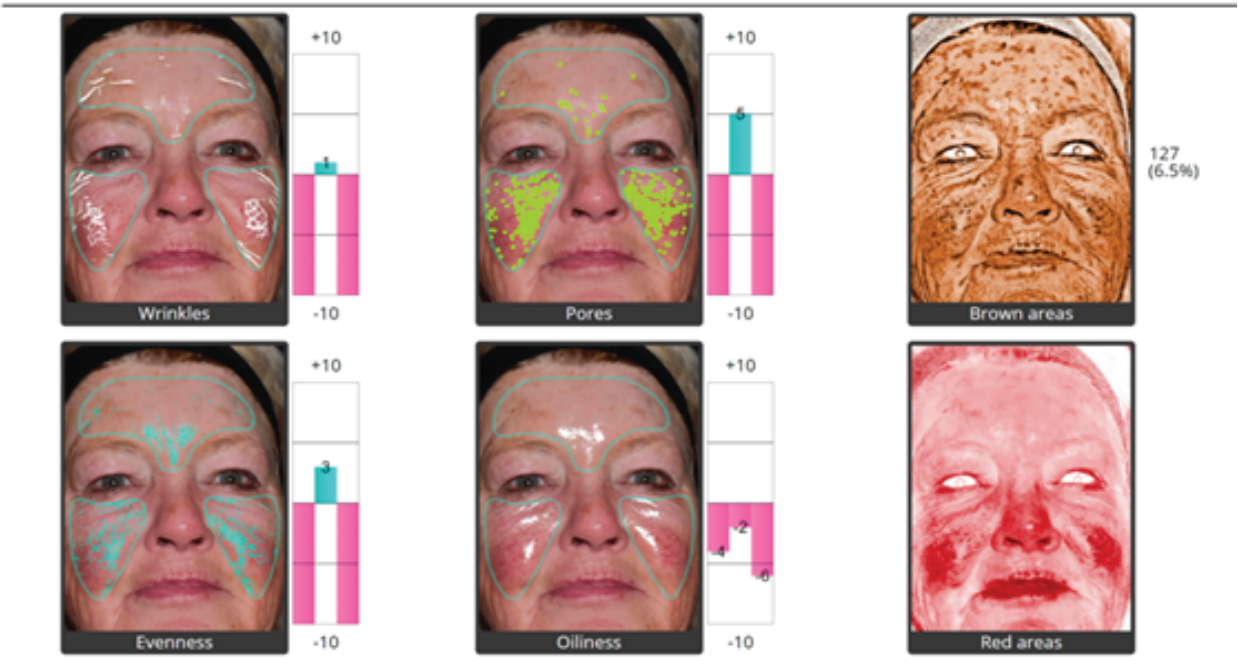

Skincare Analysis after-Hydrating facial-Note minimal change in graphs.

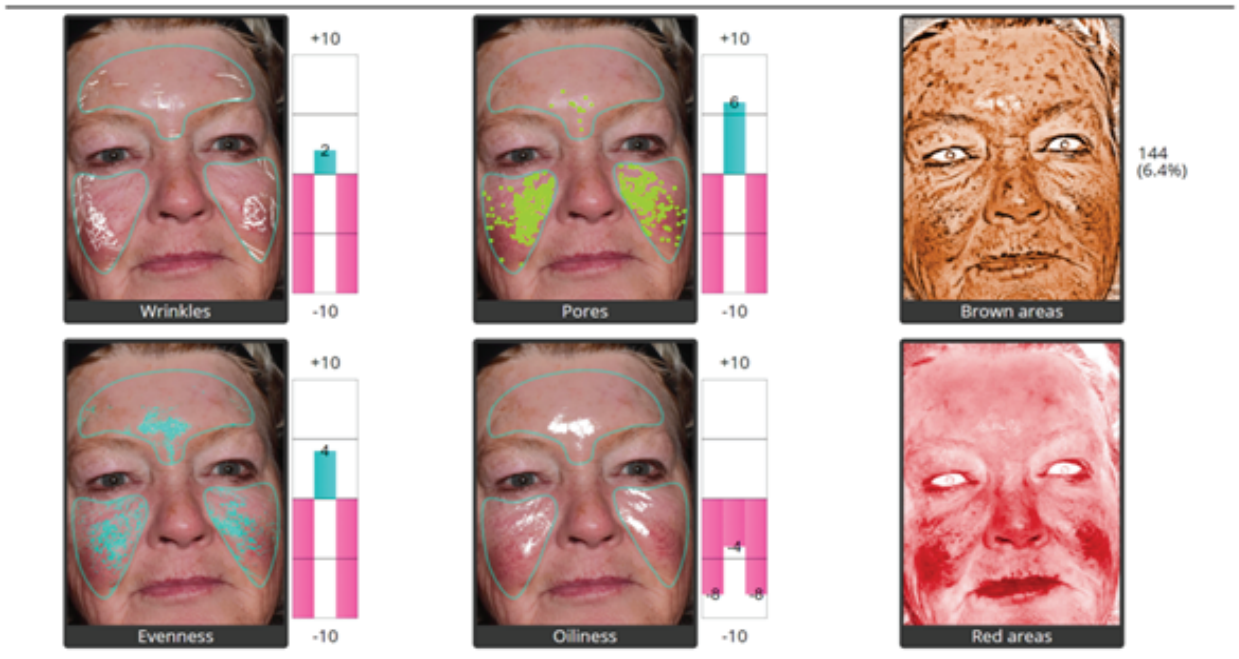

Figure 4: Skincare analysis before and after-hydrating facial

In 2011, the U.S. Departments of Agriculture, Health and Human Services issued their $7^{\text {th }}$ edition of the Dietary Guidelines for Americans [2]. They listed twelve vitamins and nine minerals recognized as necessary for health and well-being. Sea salt contains all of these essential minerals. (Table 7) lists the mineral goals for adults based on dietary reference intakes and dietary guideline recommendations [2]. Biochemically, many enzymes require the presence of metal ions for catalytic activity. (Table 8) lists examples of several important metalloenzymes [2]. Early studies examined the oral intake benefits of the essential minerals, while more recently, the benefits of topically applied mineral salts have been studied [8]. The presence of these minerals in the sea salt contributes to the benefit of the SaltFacial over standard microdermabrasion.

Calcium is the most abundant mineral in the human body [9-13] Its key roles include hemostasis and regulating epithelialization. It plays a large role in wound healing by regulating keratinocytes [1012]. Calcium is essential in maintaining skin's barrier function, playing a major role in skin barrier repair. Barrier thickening assists skin in retaining moisture, thereby reducing visible wrinkles and dryness. This explains the improving Quantificare profiles of patients receiving the salt therapy.

Potassium [14] and sodium [15] are the bodies' major cellular and extracellular electrolytes. In this role, they maintain cellular membrane potential. The positive electrolyte benefits to skin of bathing in the Dead Sea have been heralded for centuries [16].

Magnesium is critical for energy metabolism, cell replication, and skin barrier repair with calcium regulating keratinocyte function and production [17-25]. Two popular consumer products containing magnesium are talcum powder (magnesium silicate) and epsom salts $\left(\mathrm{MgSO}_{4}\right)$. Talc is used as an astringent in baby powder, reducing wetness, in the perineal and axillary regions, while enhancing the smoothness of skin on other body areas. Epsom salts acts as a laxative internally, while enhancing keratinocyte softening and exfoliation when bathed in. It has been known as the relaxation mineral, activating 
Skincare analysis before SaltFacial.
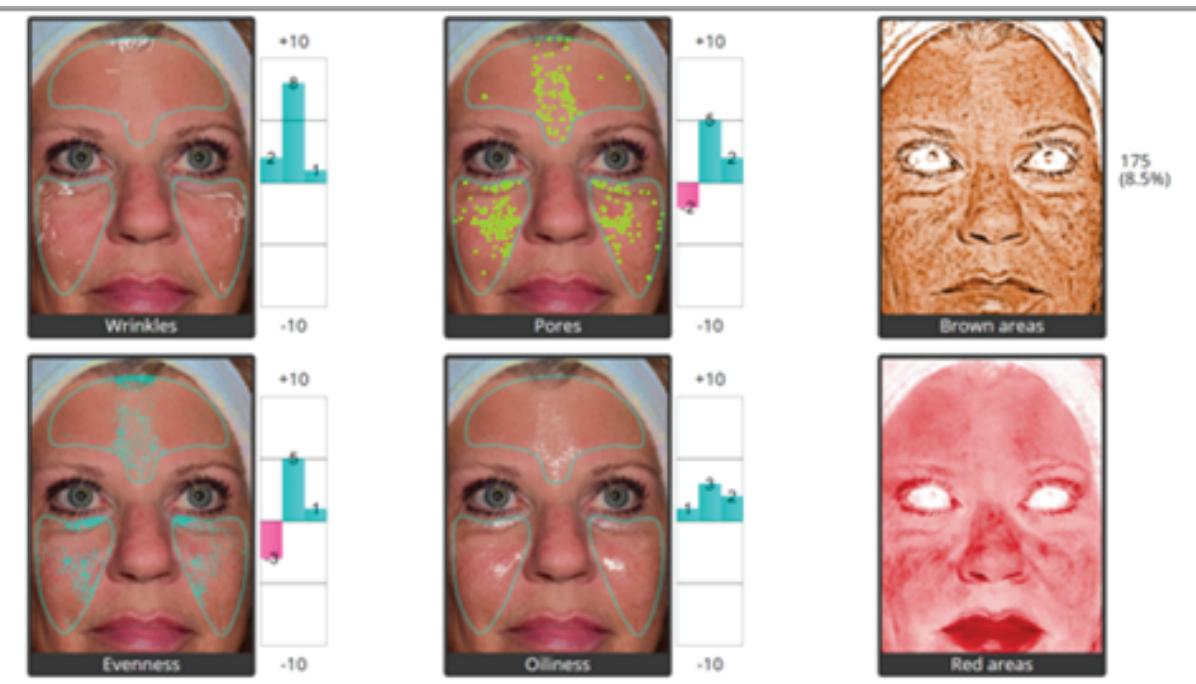

Skincare Analysis and Photos 120 Days after 3 SaltFacial Treatments: Note Graph Improvement.
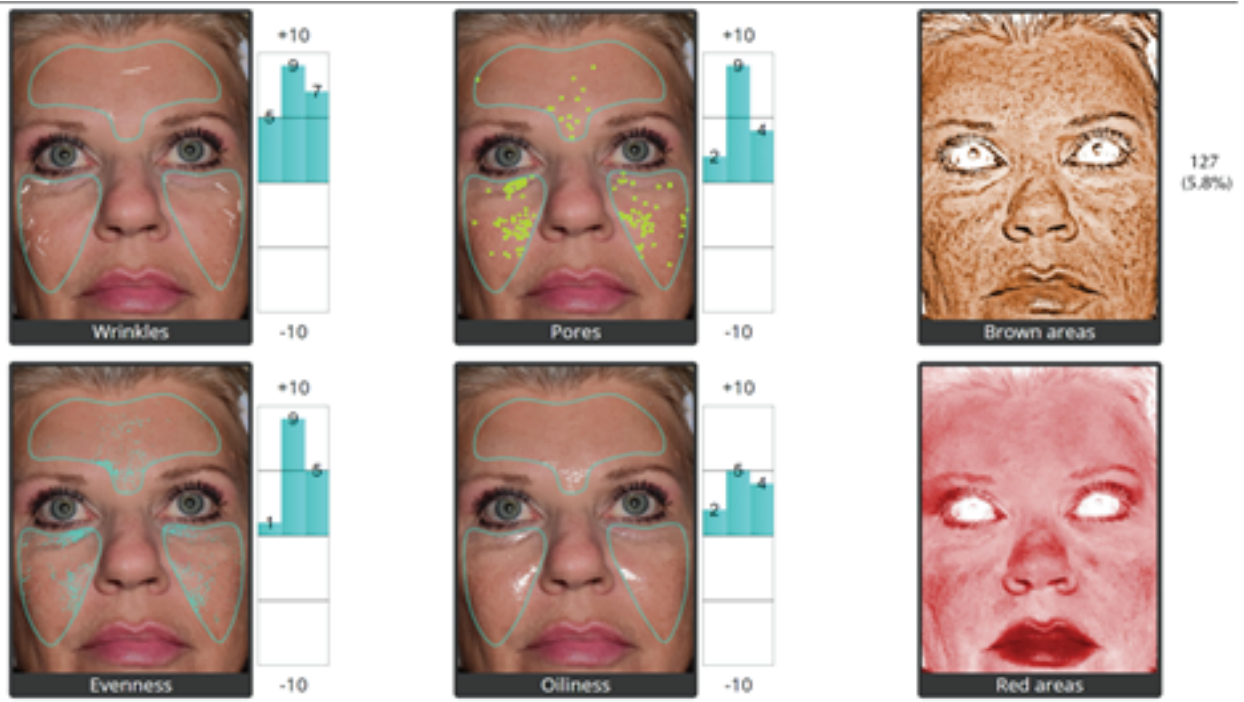

Figure 5: Aging skin patient

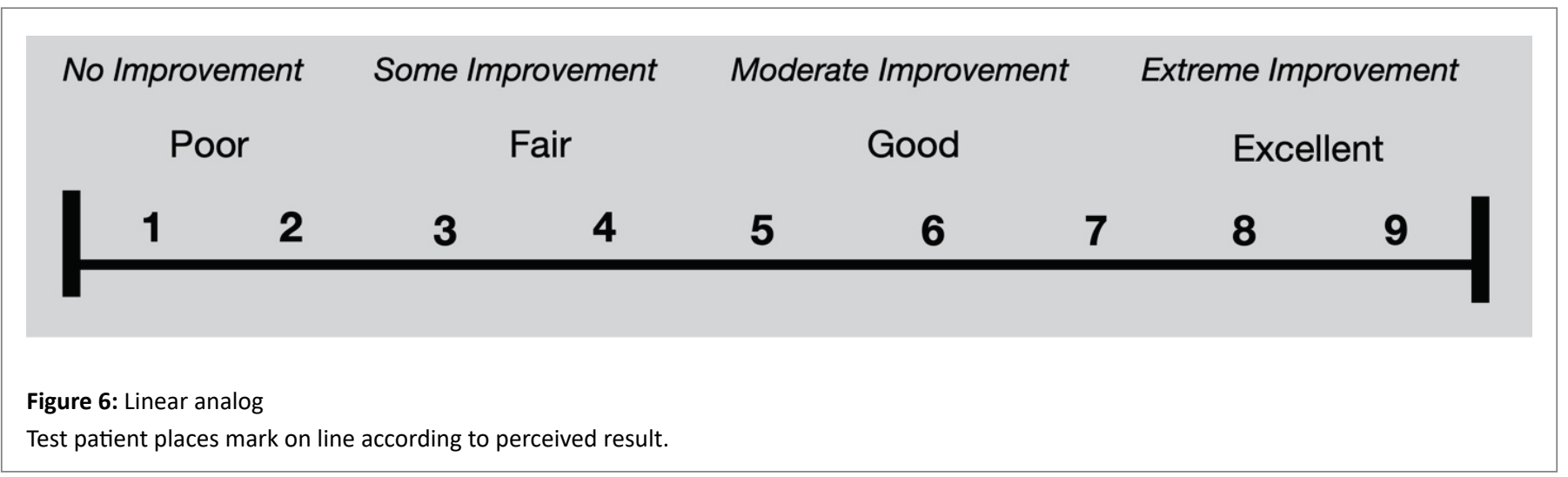


Table 3: Acne Patients: Summarizes the results of the patient administrated linear analog tests for satisfaction.

\begin{tabular}{|l|c|c|c|c|}
\hline \multirow{2}{*}{ Satisfaction } & \multicolumn{4}{|c|}{ Percent } \\
\cline { 2 - 5 } & 7 Days & 14 Days & 21 Days & 28 Days \\
\hline Unhappy & 0 & 0 & 0 & 0 \\
\hline Satisfied & 62.5 & 12.5 & 12.5 & 0 \\
\hline Very Satisfied & 25 & 50 & 25 & 12.5 \\
\hline Extremely Satisfied & 12.5 & 37.5 & 62.5 & 87.5 \\
\hline
\end{tabular}

Table 4: Infection Patients: Number of days healing compared to controlAntibiotic alone patients.

\begin{tabular}{|c|c|c|c|}
\hline Salt Facial & \#Days & Antibiotics & \#Days \\
\hline 1 & 6 & 1 & 10 \\
\hline 2 & 5 & 2 & 12 \\
\hline 3 & 7 & 3 & 9 \\
\hline 4 & 8 & 4 & 14 \\
\hline 5 & 5 & 5 & 12 \\
\hline 6 & 7 & 6 & 10 \\
\hline 7 & 4 & 7 & 13 \\
\hline 8 & 5 & 8 & 11 \\
\hline
\end{tabular}

Table 5: Infection Patients: Summarizes the results of patient's administrated linear analog tests for satisfaction.

\begin{tabular}{|l|c|}
\hline Satisfaction & Percent \\
\hline Unhappy & 0 \\
\hline Satisfied & 0 \\
\hline Very Satisfied & 12.5 \\
\hline Extremely Satisfied & 87.5 \\
\hline
\end{tabular}

Table 6: Wound Healing: Number of days healing compared to control.

\begin{tabular}{|c|c|c|c|}
\hline SaltFacial & \#Days & Control & \#Days \\
\hline 1 & 6 & 1 & 10 \\
\hline 2 & 7 & 2 & 14 \\
\hline 3 & 9 & 3 & 16 \\
\hline 4 & 10 & 4 & 12 \\
\hline 5 & 7 & 5 & 10 \\
\hline 6 & 8 & 6 & 7 \\
\hline 7 & 5 & 7 & 10 \\
\hline 8 & 8 & 8 & 12 \\
\hline 9 & 7 & 9 & 15 \\
\hline 10 & 6 & 10 & 13 \\
\hline 11 & 5 & 11 & 12 \\
\hline 12 & 5 & 12 & 10 \\
\hline 13 & 7 & 13 & 16 \\
\hline 14 & 8 & 14 & 10 \\
\hline 15 & 10 & 15 & 9 \\
\hline 16 & 7 & 16 & 8 \\
\hline 17 & 6 & 17 & 7 \\
\hline 18 & 8 & 18 & 10 \\
\hline 19 & 5 & 19 & 11 \\
\hline 20 & 5 & 20 & 10 \\
\hline
\end{tabular}

Table 7: Mineral goals for adults based on dietary reference intakes.

\begin{tabular}{|l|c|c|c|c|}
\hline \multirow{2}{*}{ Mineral } & Female & Male & Female & Male \\
\cline { 2 - 5 } & $\mathbf{1 9 - 5 0}$ year & $\mathbf{1 9 - 5 0}$ year & $\mathbf{5 1 + y e a r}$ & 51+year \\
\hline Calcium (mg) & 1000 & 1000 & 1200 & 1200 \\
\hline Iron (mg) & 18 & 8 & 8 & 8 \\
\hline Magnesium (mg) & $310-320$ & $400-420$ & 320 & 420 \\
\hline Phosphorus (mg) & 700 & 700 & 700 & 700 \\
\hline Potassium (mg) & 4700 & 4700 & 4700 & 4700 \\
\hline Sodium (mg) & $<2300$ & $<2300$ & $<2300$ & $<2300$ \\
\hline Zinc (mg) & 8 & 11 & 8 & 11 \\
\hline Copper $(\mu \mathrm{g})$ & 900 & 900 & 900 & 900 \\
\hline Selenium $(\mu \mathrm{g})$ & 55 & 55 & 55 & 55 \\
\hline
\end{tabular}

Table 8: Metalloenzymes.

\begin{tabular}{|c|c|c|}
\hline Element & Metalloenzyme & Function \\
\hline \multirow{5}{*}{$\mathrm{Cu}$} & Superoxide Dismutase & $\begin{array}{c}\text { Superoxide decomposition } \\
\text { (Antioxidant) }\end{array}$ \\
\hline & Lysyl Oxidase & Collagen, Elastin synthesis \\
\hline & Collagen Proline Dioxygenase & Collagen synthesis \\
\hline & Cytochrome Oxidase & Energy production \\
\hline & Tyrosinase & Melanin formation \\
\hline \multirow{2}{*}{$\mathrm{Fe}$} & Cytochrome C Reductase & Energy production \\
\hline & Aconitase & Intermediary metabolism \\
\hline \multirow{3}{*}{$\mathrm{Mg}$} & Glucose 6-Phosphatase & Intermediary metabolism \\
\hline & Aconitase & Intermediary metabolism \\
\hline & Hexokinase & Intermediary metabolism \\
\hline $\mathrm{Mn}$ & Catalase & $\begin{array}{l}\text { Peroxide decomposition } \\
\text { (Antioxidant) }\end{array}$ \\
\hline $\mathrm{Se}$ & Glutathione Peroxidase & $\begin{array}{l}\text { Peroxide decomposition } \\
\text { (Antioxidant) }\end{array}$ \\
\hline \multirow{4}{*}{ Zn } & Matrix Metalloproteases & $\begin{array}{c}\text { Matrix remodeling, Wound } \\
\text { healing }\end{array}$ \\
\hline & Numerous Protein Kinases & Signal Transduction \\
\hline & Numerous tRNA synthases & t RNA synthesis \\
\hline & DNA/RNA Polymerase & DNA/RNA synthesis \\
\hline
\end{tabular}

the parasympathetic system and subsequently reducing oxidative stress [21].

Zinc is a prominent cofactor for many enzymes (Table 8), especially those involved in wound healing [26-29]. The use of many zinc salts is FDA-approved for treating numerous conditions [27]. Most common are sunscreens, dandruff treatments, and anti-fungal preparations.

Iron is one of the most abundant trace minerals in the body. It is most important in cellular oxygen transportation and oxygenreduction reactions involved with respiration [30-35]. Approximately $70 \%$ of the body's iron is associated with hemoglobin.

Copper is an important trace mineral found throughout the body. It serves as a coenzyme for many enzymes including lysyl oxidase, 
Skincare analysis and photos before SaltFacial treatment.
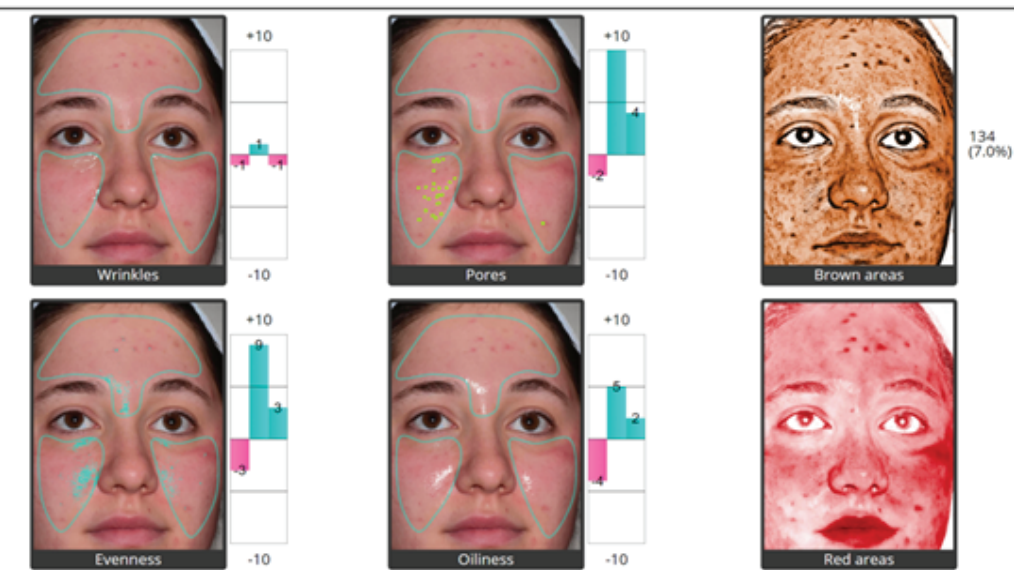

Skincare analysis 28 days after $3^{\text {rd }}$ SaltFacial treatment: Reduced pustules, improved complexion.
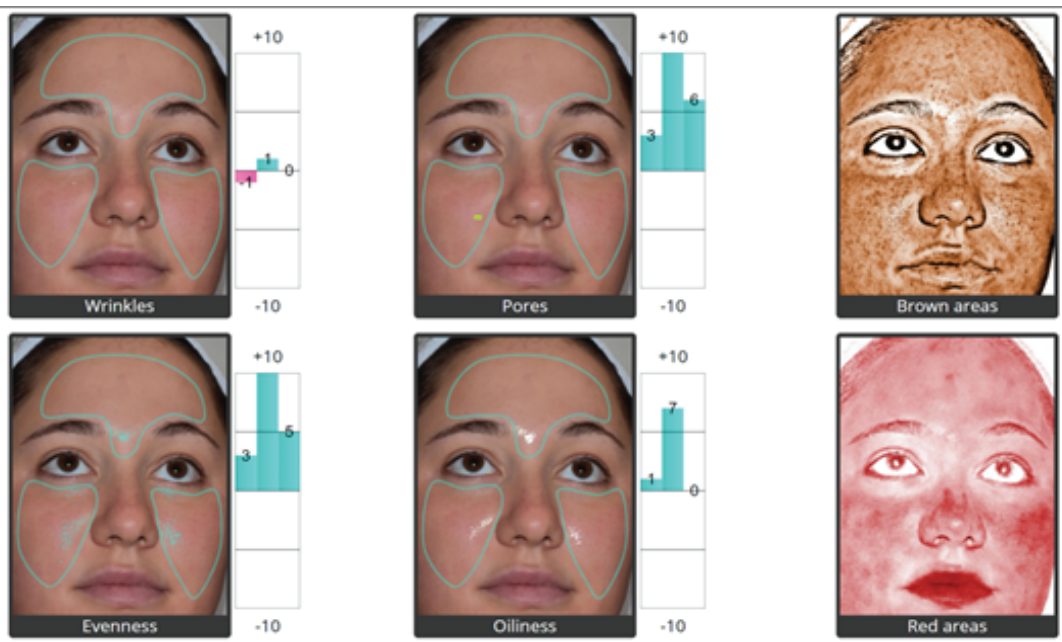

Figure 7: Acne patient.

Before SaltFacial and 28 days after $3^{\text {rd }}$ SaltFacial treatment: Reduced.
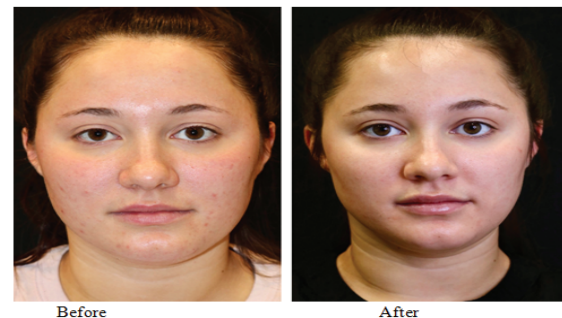

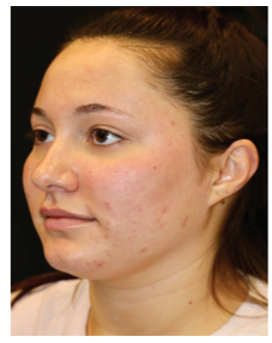

Before

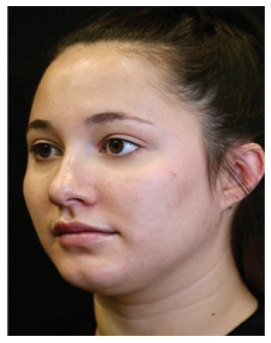

After

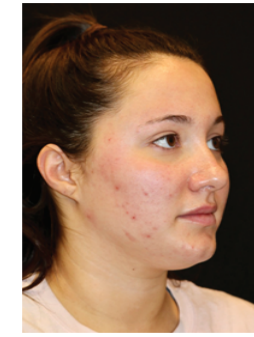

Before

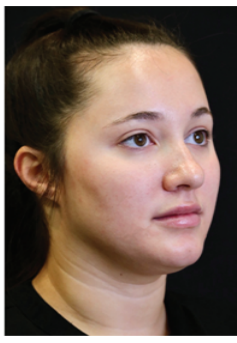

After

Figure 8: Acne patient. 
Day 2 post surgery.

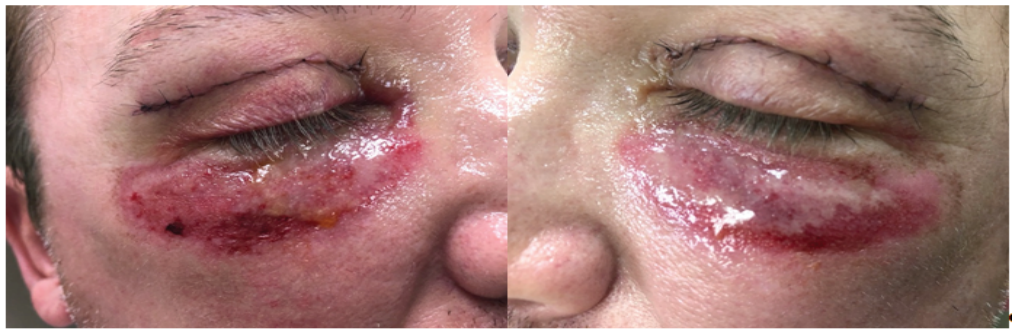

Resolution of MRSA infection 5 days post-surgery after daily LED therapy using the SaltFacial system.

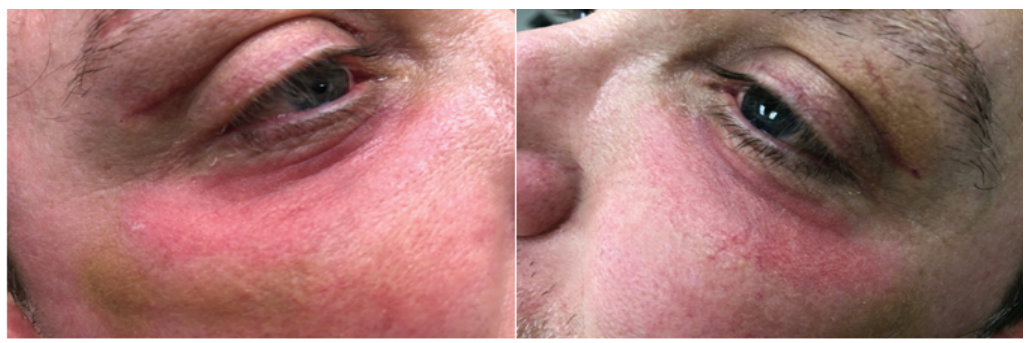

Figure 9: MRSA infected patient.

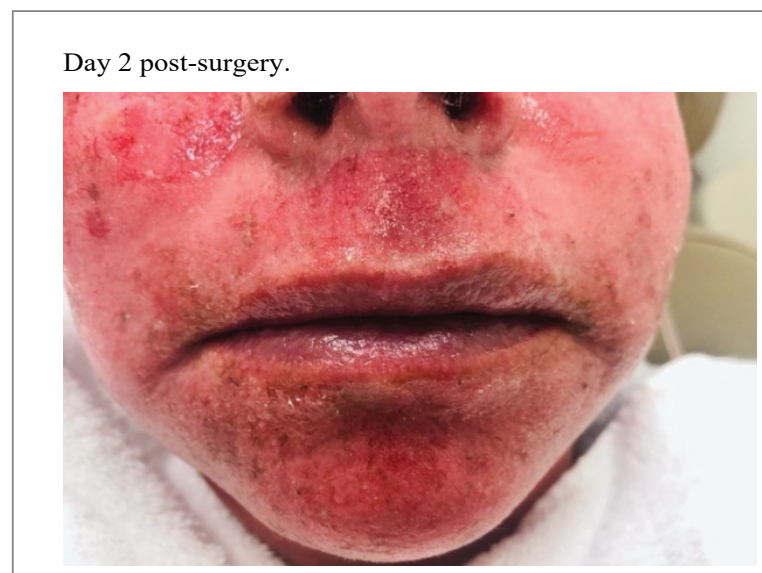

Re-epithelialization and decreased edema-Day 6 post-surgery.

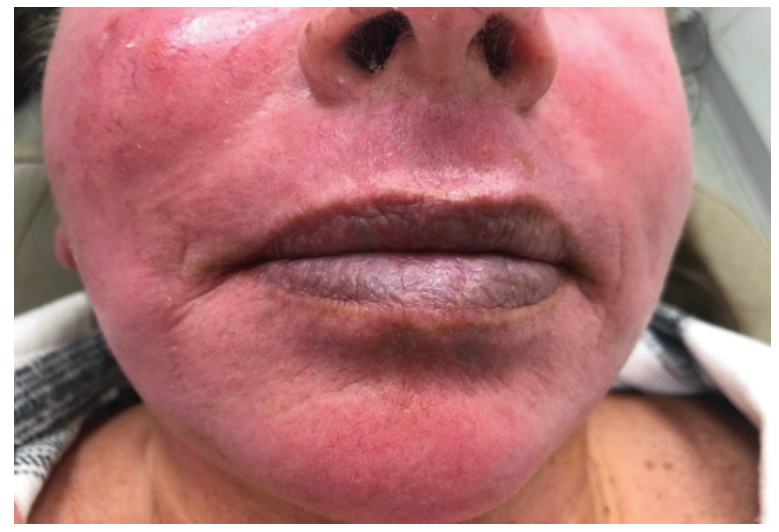

Figure 10: Wound healing patient (Facelift and skin resurfacing). responsible for cross-linking collagen, and tyrosinase, the enzyme involved in skin pigmentation. Several copper peptide complexes have been shown to calm irritated skin, improve elasticity, firmness, and accelerate wound healing [36]. Other copper compounds have shown antibacterial, anti-fungal, and antiviral properties [37].

Selenium is believed to protect the skin via it's involvement with two antioxidant enzymes, glutathione peroxidase and thioredoxin reductase [38]. Human fibroblasts, keratinocytes and melanocytes express numerous selenoproteins essential for the well-being of skin [39].

Topical salt minerals therefore act as a nontoxic exfoliant, possessing natural antiseptic properties, killing pathogens and detoxifying skin while absorbing impurities and maintaining the normal microbiome of skin. The barrier protective function regulates transepidermal water loss preventing dryness and minimizing the appearance of wrinkles.

This unique delivery device, compared to traditional microdermabrasion devices, provides for a non-thermal customizable exfoliation and sea salt/mineral delivery, with the ability of fine tuning the intensity and depth of exfoliation from the stratum corneum to the reticular dermis. The positive pressure, no vacuum/suction handpiece eliminates the risk of suction-based adverse events, making it safe for all skin types. The handpiece angle of impact allows for efficient and uniform delivery of salt with little to no patient discomfort.

Why ultrasound? There have been many papers examining the benefits of cutaneous ultrasound for enhanced dermal delivery, stimulating neocollagenesis, elastin remodeling, as well as lipoapoptosis [40-54]. Utilizing $30 \mathrm{MHz}$, pulsed delivery ultrasound provides a cavitation effect, increasing intercellular spaces thereby propelling agents through the stratum corneum and increasing passive epidermal and dermal permeability to topically applied materials.

When focused on subcutaneous tissues, the tissue can reach temperatures exceeding 60 degrees celsius yielding small coagulation points to a $5 \mathrm{~mm}$ depth within the mid to deep reticular dermis, while 
leaving the epidermis and papillary dermis unaffected [55,56]. This can result in deep reticular collagen fiber denaturing, contraction, and neocollagenesis [44]. Clinically, as evidenced in this paper, this correlates with a "skin polishing" or "air brushing" effect yielding a reduction in fine lines, increased clarity and quality of skin and improved permeability with barrier restoration.

Why LED phototherapy? The past decade has seen further refinements in the utilization of light emitting diodes (LED) in the treatment of medical and aesthetic conditions [6,57-67]. LED phototherapy has been shown to have a broad utility in a wide variety of medical, aesthetic and surgical procedures. Their safety is one of the most attractive features of LED therapy. When used alone (without topical sensitizers), they are nonablative and nonthermal, and do not cause damage in the epidermis or dermis. Depending upon the desired outcome, and the target chromophore, different wavelengths of light are employed [57].

The most common wavelengths studied include blue, red, amber and infrared or near infrared. Blue light $(414 \mathrm{~nm})$ has been widely shown to possess antibacterial properties, particularly against $\mathrm{p}$. acnes, clostridium, staph aureus and MRSA [57-59]. This was shown repeatedly in this study. Red light $(660 \mathrm{~nm})$ stimulates mitochondrial and fibroblast activity, increasing cellular proliferation, promoting healing, and reducing inflammation and erythema [60], also evidenced in our patient population. When combined together, antibacterial efficacy is improved [61]. Amber light (590nm) was also found to contribute to reducing inflammation and erythema. Further studies revealed that infrared $(830 \mathrm{~nm})$ and near infrared $(930 \mathrm{~nm})$ aided with vasodilation and stimulated fibroblastic activity and collagen production, further enhancing wound healing. This magnified the benefits of Red light [62-67]. This was successfully shown in our postoperative patient population.

Several technological advancements distinguish the LED system utilized in this study. The LED module features 3 large adjustable wraparound panels, each containing 1750 semi-coherent LED's utilizing spectral power- (no scatter); with precision endpoint focused, wavelength specific, LED therapy. This yields a more concentrated, focused and powerful light emission (semi-coherent), capable of treating the face and neck simultaneously [68].

The wavelengths are pre-programmed into 4 specific treatment modes:

1. Acne therapy-combination of blue and red (20 minutes)

2. Photodynamic therapy (PDT)- blue ( 9 minutes)

3. Collagen restoration-combination of red and NIR (20 minutes)

4. Skin rejuvenation-combination of red and amber (20 minutes)

This paper has shown the synergistic positive effect of combining these three modalities for many aesthetic dermatological and surgical scenarios, including:

1. Maintenance of healthy skin physiology

2. Aging skin improvement

3. Acne therapy

4. "Covid 19 Era" tissue cleansing improving patient confidence

5. Pre and post procedure tissue cleansing (implants, threads)

6. Pre and post botulinum/filler injection edema reduction

7. Post-procedure reduction of edema, erythema, purpura, and pain
8. Improving scalp vascularity/hair growth

9. Reducing active infection time of healing

10. Pain mitigation

11. Successful "non-energy" form of skin rejuvenation

12. Pre- non-surgical ultrasound body sculpting (removal of stratum corneum prior, enhances ultrasound penetration and efficacy)

\section{Conclusion}

This study has shown the synergistic effect of combining sea salt exfoliation, cavitating dermal permeability enhancing ultrasound, and high intensity, endpoint focused, wavelength specific LED therapying in treating a variety of common aesthetic, medical, dermatological and surgical conditions. This combination therapy is a viable and valuable addition to the armamentarium of aesthetic non-surgical treatments to safely and effectively offer to patients of all ages and Fitzpatrick Skin Types 1 through 6 . Additionally, it is a treatment that is performed by ancillary staff, thereby allowing the managing physician to treat other patients while this treatment is being performed.

Further study will yield enhancements in the efficacy of this valuable combination therapy.

\section{References}

1. Kurlansky M (2003) Salt: A World History. Penguin Books London England.

2. TG Polefka, RJ Bianchini, S Shapiro (2012) Interaction of mineral salts with the skin: a literature survey.Int J Cosmet Sci 34: 416-423.

3. Miller D, SmithN,Bailey M,Czarnota G, Hynynen K, et al. (2012) Overview of Therapeutic Ultrasound Applications and Safety Considerations.J Ultrasound Med 31: 623-634.

4. Coussios CC,Farny CH, Haar GT, Roy RA (2007) Role of acoustic cavitation in the delivery and monitoring of cancer treatment by high-intensity focused ultrasound (HIFU). Int J Hyperthermia 23: 105-20.

5. Bani D, Li AQ, Freschi G,Russo GL (2013) Histological and Ultrastructural Effects of Ultrasound-induced Cavitation on Human Skin Adipose Tissue. PlastReconstrSurg Glob Open 7: e41.

6. Ablong (2018) Phototherapy with Light Emitting Diodes: Treating a Broad Range of Medical and Aesthetic Conditions in Dermatology. J ClinAesthetDermatol 11: 21-27.

7. Chernoff $\mathrm{G}$ (2020) The Utilization of a Nitric Oxide Generating Serum in the Treatment of Active Acne and Acne Scarred Patients. Int J Pharma Anal Acta 3: 010-014.

8. Lansdown AB (1995) Physiological and toxicological changes in the skin resulting from the action and interaction of metal ions. CRC Crit Rev Toxicol25: 397-462.

9. Lansdown ABG (2002) Calcium: a potential central regulator in wound healing in the skin. Wound Repair Regen 10: 271-285.

10. Higdon J, Drake VJ (2012) Calcium: An Evidence-Based Approach to Vitamins and Minerals.( $\left({ }^{\text {nd }}\right.$ edtn) Georg ThiemeVerlag, Stuttgart, Germany 115-127.

11. Elias PM, Ahn SK, Brown BE, Crumrine D, Feingold KR (2002) Origin of the epidermal calcium gradient: regulation by barrier status and role of active vs. passive mechanisms. J Invest Dermatol 119: 12691274.

12. Elias PM,Ahn SK, Denda M, Brown BE, Crumrine D, et al. (2002) Modulations in epidermal calcium regulatethe expression of differentiation-specific markers. J Invest Dermatol 119:1128-1136. 
13. Fang K S, Farboud B, Nuccitelli R, Isseroff RR (1998) Migration of human keratino-cytes in electric fields requires growth factors and extracellular calcium. J Invest Dermatol 111: 751-756.

14. Treviño, MA, Herrmann GH, Sprout WL (1983) Treatment of severe hydrofluoric acid exposures. J Occup Med 25: 861-863.

15. Higdon J, Drake VJ (2012) Potassium: An Evidence-Based Approach to Vitamins and Minerals. (2 ${ }^{\text {nd }}$ edtn) Georg ThiemeVerlag, Stuttgart, Germany 196-213.

16. Higdon J, Drake VJ (2012) Sodium (Chloride): An Evidence-Based Approach to Vitamins and Minerals. ( $2^{\text {nd }}$ edtn) Georg ThiemeVerlag, Stuttgart, Germany 214-223.

17. Matz H, Orion E, Wolf R (2003) Balneotherapy in dermatology. DermatolTher 16: 132-140.

18. Fawcett W, HaxbyE, Male D (1999) Magnesium: physiology and pharmacology. Br J Anaesth 83: 302-320.

19. Higdon J, Drake VJ (2012) Magnesium: An Evidence-Based Approach to Vitamins and Minerals. ( $2^{\text {nd }}$ edtn) Georg ThiemeVerlag, Stuttgart, Germany 169-178.

20. Muscat JE, Huncharek MS (2008) Perineal talc use and ovarian cancer: a critical review. Eur J Cancer Prev 17: 139-146.

21. Boisseau AM, Donatien P, Surlève-Bazeille JE, Amédée J, Harmand MF, et al. (1992) Production of epidermal sheets in a serum free culture system: a further appraisal of the role of extracellular calcium. J Dermatol Sci 3: 111-120.

22. Denda M, Katagiri C, Hirao T, Maruyama N, Takahashi M (1999) Some magnesium salts and a mixture of magnesium and calcium salts accelerate skin barrier recovery. Arch Dermatol Res 291: 560563.

23. Schempp CM, Dittmar HC, Hummler D, Haarhaus BS, Mönting JS, et al. (2000) Magnesium ions inhibit the antigen-presenting function of human epidermal Langerhans cells in vivo and in vitro: involvement of ATPase, HLA-DR, B7 molecules, and cytokines. J Invest Dermatol 115: 680-686

24. Nasermoaddeli A, Kagamimori S (2005) Balneotherapy in medicine: a review. Environ Health Prev Med 10: 171-179.

25. Charlier R, Chaineux MP (2009) The healing sea: a sustainable Coastal Ocean resource: thalassotherapy. JCoast Res 25: 838-856.

26. Proksch E, Nissen HP, Bremgartner M, Urquhart C (2005) Bathing in a magnesium-rich Dead Sea salt solution improves skin barrier function, enhances skin hydration, and reduces inflammation in atopic dry skin. Intl J Dermatol 44: 151-157.

27. Tapiero H, Tew KD (2003) Trace elements in human physiology and pathology: zinc and metallothioneins. Biomed Pharmacother 57: 399-411.

28. Schwartz JR, Marsh RG, Draelos ZD (2005) Zinc and skin health: overview of physiology and pharmacology. DermatolSurg 31: 837847.

29. Lansdown ABG, Mirastschijski U, Stubbs N, Scanlon E, Agren MS (2007) Zinc in wound healing: theoretical, experimental, and clinical aspects. Wound Repair Regen 15: 2-16.

30. Powell SR (2000) Zinc and Health: current Status and Future Directions. J Nutr 130: 1447S-1454S.

31. Lansdown ABG (2001) Iron: a cosmetic constituent but an essential nutrient for healthy skin. Int J Cosmet Sci 23: 129-137.

32. Higdon J, Drake VJ (2012) Iron: An Evidence Based Approach to Vitamins and Minerals. ( $2^{\text {nd }}$ edtn) Georg ThiemeVerlag, Stuttgart, Germany 157-168.
33. Molin L, Wester P (1973) Iron content in normal and psoriatic epidermis. ActaDermVenereol 53: 473-476.

34. Draelos D (2000) Colored facial cosmetics. DermatolClin 18: 621 631.

35. Bissett DL, McBride JF (1992) Iron content of human epidermis from sun-exposed and non-exposed body sites. J SocCosmetChem 43 215-217.

36. Higdon J, Drake VJ (2012) Copper: An Evidence-Based Approach to Vitamins and Minerals. Georg ThiemeVerlag, (2 ${ }^{\text {nd }}$ edtn) Georg ThiemeVerlag, Stuttgart, Germany 135-141.

37. Mazurowska L, Mojski M (2008) Biological activities of selected peptides: skin penetration ability of copper complexes with peptides. J Cosmet Sci 59: 59-69.

38. Borkow G, Gabbay J (2009) Copper: An ancient remedy returning to fight microbial, fungal and viral infections. Cur ChemBiol 3: 272-278.

39. Burke KE (2008) Prevention and treatment of aging skin with topical antioxidants. Skin Aging Handbook: An Integrated Approach to Biochemistry and Product Development. (Dayan N edtn) William Andrew Inc, Norwich, NY, 149-176.

40. Sengupta A, Lichti UF, Carlson BA, Ryscavage AO, Gladyshev VN, et al. (2010) Selenoproteins are essential for proper keratinocyte function and skin development. PLoS One 5: e12249.

41. Clement GT (2004) Perspectives in clinical uses of high-intensity focused ultrasound. Ultrasonic 42: 1087-1093.

42. Kapoor R, Shome D, Ranjan A (2017) Use of a novel combined radiofrequency and ultrasound device for lipolysis, skin tightening and cellulite treatment. J Cosmet Laser Ther 19: 266-274.

43. Fabi SG (2015) Noninvasive skin tightening: focus on new ultrasound techniques. ClinCosmetInvestigDermatol 8: 47-52.

44. Kim KH, Geronemus RG (2004) Nonablative laser and light therapies for skin rejuvenation. Arch Facial PlastSurg 6: 398-409.

45. Minkis K, Alam M (2014) Ultrasound skin tightening. DermatolClin 32: 71-77.

46. Suh DH, Shin MK, Lee SJ, Rho JH, Lee MH, et al. (2011) Intense focused ultrasound tightening in Aasian skin:clinical and pathologic results. DermatolSurg 37: 1595-1602.

47. Gliklich RE, White WM, Slayton MH, Barthe PG, Makin IR (2007) Clinical pilot study of intense ultrasound therapy to deep derma facial skin and subcutaneous tissues. Arch Facial PlastSurg 9: 88-95.

48. Boucaud A (2004) Trends in the use of ultrasound-mediated transdermal drug delivery. Drug Discov Today 9: 827-828.

49. Pitt WG, Husseini GA, Staples BJ (2004) Ultrasonic drug delivery:a general review. Expert Opin Drug Deliv 1: 37-56.

50. Mitragotri S, Kost J (2004) Low-frequency sonophoresis: a review. Adv Drug Deliv Rev 56: 589-601.

51. Farinha A, Kellogg S, Dickinson K, Davison T (2006) Skin impedance reduction for electrophysiology measurements using ultrasonic skin permeation: initial report and comparison to current methods. Biomed Instrum. Technol 40: 72-77.

52. Mitragotri S, Edwards DA, Blankschtein D, Langer R (1995) A mechanistic study of ultrasonically-enhanced transdermal drug delivery. J Pharm Sci 84: 697-706.

53. Coleman KM, Coleman WP $3^{\text {rd }}$, Benchetrit A (2009) Non-invasive, external ultrasonic lipolysis. SeminCutan Med Surg28: 263-267. 
54. Teitelbaum SA, Burns JL, Kubota J, Matsuda H, Otto MJ, et al. (2007) Noninvasive body contouring by focused ultrasound: safety and efficacy of the Contour I device in a multicenter, controlled, clinical study. PlastReconstrSurg120: 779-789.

55. Garcia O Jr, Schafer M (2013) The effects of nonfocused external ultrasound on tissue temperature and adipocyte morphology. AesthetSurg J 33: 117-127.

56. Bozec L, Odlyha M (2011) Thermal denaturation studies of collagen by microthermal analysis and atomic force microscopy. Biophys J 101: 228-236.

57. White WM, Makin IR, Barthe PG, Slayton MH, Gliklich RE (2007) Selective creation of thermal injury zones in the superficial musculoaponeurotic system using intense ultrasound therapy: a new target for noninvasive facial rejuvenation. Arch Facial PlastSurg 9: 22-29.

58. Calderhead RG (2007) Thephotobiological basics behind lightemitting diode (LED) phototherapy. Laser Ther 16: 97-108.

59. Ashkenazi H, Malik Z, Harth Y, Nitzan Y (2003) Eradication of Propionibacterium acnes by its endogenic porphyrins after illumination with high intensity blue light. FEMS Immunol Med Microbiol 35: 17-24.

60. Morton CA, Scholefield RD, Whitehurst C, Birch J (2005) An open study to determine the efficacy of blue light in the treatment of mild to moderate acne. J Dermatolog Treat 16: 219-223.

61. Papageorgiou P, Katsambas A, Chu A (2000) Phototherapy with blue $(415 \mathrm{~nm})$ and red $(660 \mathrm{~nm})$ light in the treatment of acne vulgaris. $\mathrm{Br}$ J Dermatol 142: 973-978.
62. Goldberg DJ, Russell BA (2006) Combination blue $(415 \mathrm{~nm})$ and red $(633 \mathrm{~nm})$ LED phototherapy in the treatment of mild to severe acne vulgaris. J Cosmet Laser Ther 8: 71-75.

63. Trelles MA, Allones I, Mayo E (2006) Combined visible light and infrared lightemitting diode (LED) therapy enhances wound healing after laser ablative resurfacing of photodamaged facial skin. Med Laser Appl 21: 165-75.

64. Whelan HT, Buchmann EV, Dhokalia A, Kane MP, Whelan NT, et al. (2003) Effect of NASA light-emitting diode irradiation on molecular changes for wound healing in diabetic mice. J Clin Laser Med Surg 21: 67-74.

65. Trelles MA, Allones I (2006) Red lightemitting diode (LED) therapy accelerates wound healing post-blepharoplasty and periocular laser ablative resurfacing. J Cosmet Laser Ther 8: 39-42.

66. Kim JW, Lee JO (2008) Low level laser therapy and phototherapyassisted hydrogel dressing in burn wound healing: light-guided epithelial stem cell biomodulation. In: Innovations in Plastic and Aesthetic Surgery. New York: Springer: 36-41.

67. Kim JW, Lee JO, Calderhead RG (2005) The improvement of hypertrophic scar and keloidal scar by combining drilling tiny pinholes with carbon dioxide laser and $830 \mathrm{~nm}$ Omnilux PDT LED. J Korean Soc Laser Med Surg 9:1-6.

68. Kim JW, Lee JO, Calderhead RG (2005)Synergic effect of ablating erbium Yag laser skin resurfacing combined with non-ablating quasilaser light $415 \mathrm{~nm}, 633 \mathrm{~nm}, 830 \mathrm{~nm}$ LED array in Asian patients. J Korean Soc Laser Med Surg 9:15-23. 